\title{
The determination of magnesium in biological materials by flame photometry
}

\author{
J. K. FAWCETT AND V. WYNN \\ From the Surgical Unit, St. Mary's Hospital, London
}

SYNOPSIS A method is described for the measurement of magnesium in biological materials and has been applied to the Unicam flame spectrophotometer SP 900.

Samples were diluted in $10 \mathrm{mM}$ strontium ethylenedinitrolo tetraacetate (EDTASr), $10 \mathrm{mM}$ potassium carbonate, giving final magnesium concentrations of about $0 \cdot 1$ to $0.2 \mathrm{mM}$. The EDTASr almost eliminated the depression of magnesium emission by interfering anions. The potassium carbonate slightly depressed both magnesium emission and flame background, which were then virtually unaffected by further addition of cations.

Spectral interference by sodium was controlled by including $14 \mathrm{mM}$ sodium chloride in the plasma standards and making small corrections (usually under $2 \%$ ) on the basis of the plasma sodium level. The urine standards contained no sodium, but a small correction (usually about $2 \%$ ) was made on the basis of the urine sodium level. There was insufficient sodium in faeces to cause spectral interference.

Using the diluent described, added magnesium was satisfactorily recovered from plasma deproteinized with perchloric acid, urine, and faeces. When different volumes of identical samples of plasma and urine were analysed, the magnesium found was proportional to the volume of sample diluted.

The plasma magnesium levels reported for a small group of healthy people were similar to those found by previous workers.

In another paper (Fawcett and Wynn, 1961), we describe a method for the determination of calcium in biological materials by flame photometry, in which a releasing agent, magnesium sulphate, is used to release calcium emission from anion interference. We found that inorganic releasing agents were less effective when applied to magnesium emission. West and Cooke (1960), however, showed that ethylenedinitrolo tetraacetic acid (EDTA) reduced the interfering effects of anions on calcium emission, and was even more efficient in the case of magnesium. They added EDTA as the disodium salt, but sodium itself causes serious interference in magnesium estimations. We therefore tested the potentialities of other salts of EDTA.

Control of the effects of cations on the intensity of magnesium emission was sought by means which we had found satisfactory in the case of calcium emission, namely, the incorporation of a high concentration of a suitable cation.

Received for publication 9 May 1961.
An additional problem in the measurement of magnesium is spectral interference by sodium, which Alcock, MacIntyre, and Radde (1960) solved, using their laboratory-made flame spectrophotometer. They reported that the Zeiss spectrophotometer PMQ II, with flame attachment, can be modified for use in the same way. This account concerns the determination of magnesium in biological materials with a less expensive, British-made flame spectrophotometer.

\section{EXPERIMENTAL}

APPaRATUS The Unicam SP 900 flame spectrophotometer was used. It has a Meker-type burner utilizing acetylene and compressed air. The latter conveys the atomized solution from a separate spray chamber. The instrument is equipped with a fused prism monochromator and a photomultiplier detector.

The atomic emission line of magnesium, at $285.21 \mathrm{~m} \mu$, was used because of its greater selectivity than the molecular bands at $371 \mathrm{~m} \mu$ and $383 \mathrm{~m} \mu$. The emission peak 
was located by rotating the wavelength selector to give maximum deflection in the presence of magnesium. Sensitivity was found to be optimum using a lean fuel mixture (acetylene pressure, $10 \mathrm{~cm}$. water; air pressure $28 \mathrm{lb}$./in ${ }^{2}$ ). With a richer mixture (acetylene pressure, $20 \mathrm{~cm}$. water; air pressure, $28 \mathrm{lb}$./in ${ }^{2}$ ), sensitivity was decreased and the flame background was increased, but interference from anions was less. Initial experiments were carried out with both types of flame, but the leaner flame was chosen when it was found that anion interference could be controlled. The air pressure was not highly critical. The region in the flame of maximum emission was found with the centre of the slit 1 in. above the burner head.

The slit width was selected on the basis of the sensitivity required, and the effect of neighbouring emission lines. The only source of spectral interference near the magnesium line, at $285.21 \mathrm{~m} \mu$, is the almost coincident sodium line at $285.28 \mathrm{~m} \mu$. A slit width as low as $0.02 \mathrm{~mm}$. corresponds to a nominal band width of $0.07 \mathrm{~m} \mu$, even assuming perfect optical characteristics, and therefore does not exclude participation by sodium. On the other hand, slight errors in reproducing the wavelength setting may cause random variations in the contribution to the total emission by sodium. A wider slit width ensures complete inclusion of both peaks, permitting predictable 음 correction for sodium, and increases electronic stability. We found that avoiding exceptionally high electronic gain $\stackrel{5}{\rightarrow}$ settings contributed more to instrumental stability than a $\overline{0}$ high magnesium: flame background emission ratio. At a $0.08 \mathrm{~mm}$. slit width, this ratio was 0.2 with $0.2 \mathrm{mM}$ magnesium, the nominal band width was $0.3 \mathrm{~m} \mu$, and sensitivity was adequate for $1: 10$ plasma dilutions.

GALVANOMETER READINGS The calibration curves in $\vec{\theta}$ Fig. 1 show that emission was more nearly proportional to concentration in the range 0 to $0.2 \mathrm{mM}$ than in the $\vec{\omega}$ range 0 to $0.5 \mathrm{mM}$. There were significant day-to-day $\Omega$ variations in reproducing the second curve but not the first. $\frac{\rho}{0}$

Blank and standard readings were checked between every two or three readings of unknowns. Each solution : was read at least four times, and the mean of the middle two readings was calculated. If these two differed by more than $1 \%$, further readings were obtained.

When special diluting solutions were used, standard magnesium solutions were diluted in the same diluent as the samples, and this diluent was also used for setting zero on the galvanometer.

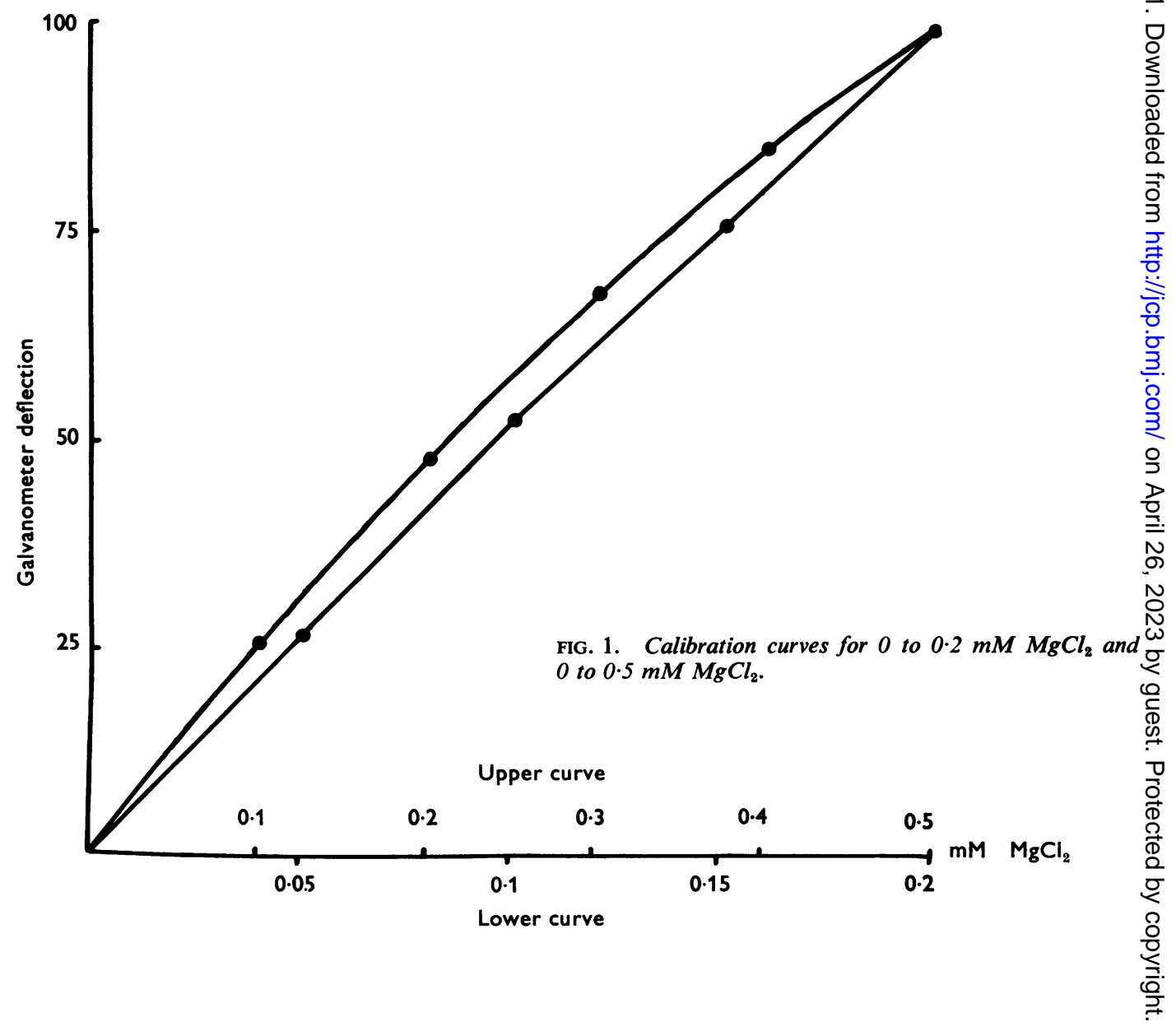


PREPARATION OF SOLUTIONS Solutions were prepared from spectroscopically pure reagents, or high purity alternatives, and deionized water.

Stock solutions containing $\mathbf{0 \cdot 1} \mathrm{M}$ magnesium were prepared in two ways: (1) from weighed magnesium ribbon dissolved in the minimum of $1.0 \mathrm{~N}$ hydrochloric acid; (2) from weighed magnesium sulphate dried to constant weight at $300^{\circ} \mathrm{C}$. When sulphate interference was controlled, as described below, $1: 500$ dilutions of these two solutions gave identical readings.

PREPARATION OF SAMPLes Samples were diluted in duplicate to give a final magnesium concentration of about 0.1 to $0.2 \mathrm{mM}$.

Plasma samples were obtained from heparinized blood. Deproteinization was necessary because the viscosity of $1: 10$ plasma dilutions reduced the flow rate through the atomiser by about $6 \%$, and this varied from one sample to another. An acid protein precipitant was used to ensure separation of protein-bound magnesium, and its concentration was kept as low as possible to minimize interference effects. Two millilitres of plasma were deproteinized with $2 \mathrm{ml}$. of $0.5 \mathrm{M}$ perchloric acid and allowed to stand for 10 minutes. Two millilitres of plasma contain only about $1.85 \mathrm{ml}$. of water, and therefore the solid content contributes an average error of $0.15 \mathrm{ml}$. in $4 \mathrm{ml}$., or $4 \%$. This error was reduced to $0.15 \mathrm{ml}$. in $16 \mathrm{ml}$., or $1 \%$, by adding $12 \mathrm{ml}$. of water before centrifuging for 10 minutes at 3,000 to 3,500 r.p.m. The supernatant solution corresponded to a $1: 8$ plasma dilution, with a $1 \%$ correction for solids.

Twenty-four-hour urine samples were preserved with $10 \mathrm{ml}$. of hydrochloric acid, and diluted $1: 25$.

Faeces were prepared by homogenizing with water, weighing, and transferring weighed portions of about $2 \mathrm{~g}$. to nickel crucibles of $50 \mathrm{~mm}$. diameter. The contents were dried at $105^{\circ}$ and ashed overnight in the uncovered crucibles at 420 to $450^{\circ}$. It was found that magnesium was lost at higher temperatures. The ash was dissolved by boiling carefully with $1 \mathrm{ml}$. of $1.0 \mathrm{~N}$ hydrochloric acid, transferred quantitatively and diluted to $100 \mathrm{ml}$. This solution was further diluted $1: 5$.

SPECTRAL INTERFERENCE FROM SODIUM Under the conditions described, $14 \mathrm{mM}$ sodium chloride gave the same emission as $0.015 \mathrm{mM}$ magnesium chloride, and this interference was directly proportional to sodium concentration. Thus in plasma the emission due to sodium represented 15 to $20 \%$ of the emission due to magnesium. In urine, which nearly always has a much lower sodium : magnesium ratio, the sodium emission was usually about 2 to $3 \%$ of the magnesium emission. The sodium content of faeces caused negligible interference.

There are three methods of controlling spectral interference by sodium: (1) chemical separation of magnesium from sodium; (2) inclusion of the same concentration of sodium chloride in the magnesium standards as its concentration in the diluted sample; (3) correction of observed magnesium readings on the basis of the sodium concentration, and of its known interference.

The first of these alternatives is time-consuming and introduces additional sources of error. The second was adopted for plasma because of its relatively constant sodium content. A concentration of $14 \mathrm{mM}$ sodium chloride was incorporated in the plasma standards, and if the plasma sodium level was known to differ significantly from $140 \mathrm{mM}$, the observed magnesium level was adjusted by $0.01 \mathrm{mM}$ (about $1 \%$ ) for each $10 \mathrm{mM}$ difference.

The third method of correction was adopted for urine because sodium interference was much smaller but more variable. For each $10 \mathrm{mM}$ sodium the urine contained, $0.01 \mathrm{mM}$ was subtracted from the observed magnesium result.

EFFECTS OF ADDED SUBSTANCES ON FLAME BACKGROUND Each of the following solutions was found to have no measurable effect on flame background at $285.2 \mathrm{~m} \mu$, under the conditions described: $10 \mathrm{mM}$ hydrochloric acid, $10 \mathrm{mM}$ sulphuric acid, $10 \mathrm{mM}$ phosphoric acid, $10 \mathrm{mM}$ perchloric acid, $10 \mathrm{mM}$ ammonia, $1 \mathrm{mM}$ calcium chloride, and $5 \mathrm{mM}$ glucose.

On the other hand, we found flame background was suppressed by potassium salts, $20 \mathrm{mM}$ potassium chloride cancelling the emission from $0.012 \mathrm{mM}$ magnesium chloride. Further increments of potassium concentration had less effect in suppressing flame background, so that $40 \mathrm{mM}$ potassium chloride cancelled the emission from only $0.017 \mathrm{mM}$ magnesium chloride.

The potassium concentration in plasma and faeces was insufficient to affect the flame background, but in urine was sufficient to cause errors of 1 to $2 \%$. When the diluting solution contained potassium, the effect of potassium in the sample was less.

Urea in pure solution also suppressed flame background but this suppression was reduced in the presence of other solutes and was negligible in urine dilutions.

EFFECTS OF ADDED SUBSTANCES ON MAGNESIUM EMISSION Preparing the samples as described, the anions causing depression of magnesium emission were phosphate, sulphate, and perchlorate. It was found that, in contrast to the enhancement of calcium emission by other cations, magnesium emission was depressed by sodium, potassium, and calcium. The effects of these ions were cumulative, so that recoveries of magnesium added to urine were only about $80 \%$.

The effect of EDTA salts, and of strontium chloride, on magnesium emission was tested before investigating their efficiency in controlling anion interference. The disodium, dipotassium, diammonium, and ferric complexes of EDTA, and strontium chloride, each depressed magnesium emission. We found, however, that the strontium salt of EDTA (EDTASr) had no effect on magnesium emission, and almost eliminated depression by added anions. Also we found that EDTASr had no effect on flame background. A concentration of $5 \mathrm{mM}$ was adequate to control expected concentrations of interfering anions, but a concentration of $10 \mathrm{mM}$ was adopted to permit a margin of safety.

Although cation interference with magnesium emission was different in direction from its interference with calcium emission, and therefore presumably different in mechanism, it seemed possible that it might reach a limiting level in the presence of excess of an interfering 
cation, as it does with calcium (Fawcett and Wynn, 1961). As we had already noted one advantage of incorporating potassium in the diluting solution, because it reduced the effect on flame background of potassium in the sample, and as its depression of magnesium emission was slight, we investigated the effects of potassium added in the form of chloride, perchlorate, hydroxide, and carbonate. These were found equally efficient in maintaining a plateau level of potassium interference and in almost eliminating depression by sodium and calcium.

The choice of which potassium compound to incorporate in the diluting solution was based upon the necessity for simultaneous control of $p \mathrm{H}$. It was found that magnesium was precipitated at high $p \mathrm{H}$ levels and that free EDTA was precipitated at low $p \mathrm{H}$ levels. A concentration of $10 \mathrm{mM}$ potassium carbonate not only provided the potassium level required to control cation interference but also maintained the $\mathrm{pH}$ of urine and faecal dilutions between 6 and 11. Additional potassium carbonate was necessary to neutralize the perchloric acid in deproteinized plasma.

CONTROL OF INTERFERENCE EFFECTS Table I shows the effects of interfering substances on magnesium emission when these were added to $0.2 \mathrm{mM}$ magnesium chloride at concentrations greater than those likely to be encountered using the dilutions described. In the presence of $10 \mathrm{mM}$ EDTASr, $10 \mathrm{mM} \mathrm{K} \mathrm{CO}_{3}$, these effects were reduced to very low levels. The cumulative depression of magnesium emission by a mixture of interfering substances, and its control in the presence of the diluting solution, are also illustrated in Table $\mathrm{I}$.

\section{TABLE I}

DEPRESSION OF EMISSION FROM $0.2 \mathrm{mM} \mathrm{MgCl}_{2}$ BY INTERFERING SUBSTANCES

\begin{tabular}{|c|c|c|c|}
\hline \multirow{2}{*}{$\begin{array}{l}\text { Interfering } \\
\text { Substance }\end{array}$} & \multirow{2}{*}{$\begin{array}{l}\text { Concentration } \\
(m M)\end{array}$} & \multicolumn{2}{|c|}{ Percentage Depression } \\
\hline & & Without Control & With Control ${ }^{1}$ \\
\hline $\mathrm{NaCl}$ & $\begin{array}{r}3 \\
15\end{array}$ & $\begin{array}{l}3 \\
5\end{array}$ & $\begin{array}{l}1 \\
1\end{array}$ \\
\hline $\mathrm{KCl}$ & $\begin{array}{l}10 \\
20 \\
30\end{array}$ & $\begin{array}{l}2 \\
3 \\
3\end{array}$ & $\begin{array}{l}0 \\
0 \\
0\end{array}$ \\
\hline $\mathrm{CaCl}_{2}$ & $\begin{array}{l}0.5 \\
1\end{array}$ & $\begin{array}{l}2 \\
3\end{array}$ & $\begin{array}{l}0 \\
1\end{array}$ \\
\hline $\mathrm{H}_{3} \mathrm{PO}_{4}$ & $\begin{array}{r}2 \\
10\end{array}$ & $\begin{array}{l}6 \\
6\end{array}$ & $\begin{array}{l}0 \\
1\end{array}$ \\
\hline $\mathrm{H}_{\mathbf{2}} \mathrm{SO}_{4}$ & $\begin{array}{r}2 \\
10\end{array}$ & $\begin{array}{l}4 \\
4\end{array}$ & $\begin{array}{l}0 \\
1\end{array}$ \\
\hline HClO, & $\begin{array}{r}50 \\
100\end{array}$ & $\begin{array}{l}11 \\
11\end{array}$ & $\begin{array}{l}1 \\
1\end{array}$ \\
\hline $\mathrm{HCl}$ & 10 & 1 & 1 \\
\hline $\begin{array}{l}\mathrm{NaCl} \\
\mathrm{KH}_{2} \mathrm{PO} \\
\mathrm{K}_{2} \mathrm{SO}_{4} \\
\mathrm{CaCl}_{3}\end{array}$ & $\left.\begin{array}{r}15 \\
10 \\
10 \\
1\end{array}\right\}$ & 20 & 2 \\
\hline
\end{tabular}

Interference was controlled by incorporating $10 \mathrm{mM}$ EDTASr, $10 \mathrm{mM} \mathrm{K}_{2} \mathrm{CO}_{3}$, in the diluting solution.
The diluting solution reduced the effect of any further $\stackrel{0}{\overrightarrow{2}}$ addition of potassium on flame background, so that with 으. a urine sample containing $50 \mathrm{mM}$ potassium, the necessary correction of the observed urine magnesium level was equivalent to only $0.01 \mathrm{mM}$ (usually less than $1 \%$ ).

DILUTING SOLuTIONS Two stock diluting solutions were prepared: A, 0.05 $\mathrm{M}$ EDTASr, 0.25 $\mathrm{M} \mathrm{K}_{2} \mathrm{CO}_{3}$, and $\mathrm{B}, \stackrel{\mathbb{D}}{\mathbb{D}}$ 0.25 M EDTASr, 0.25 $\mathrm{M} \mathrm{K}_{2} \mathrm{CO}_{3}$. Solution A was used for plasma, solution $\mathrm{B}$ for urine and faeces.

WORKING STANDARDS Two series of standards were prepared, one for plasma analysis and one for use with urine $\vec{\omega}$ and faeces. In each series, magnesium concentrations of $\mathscr{D}$ $0.05 \mathrm{mM}, 0.10 \mathrm{mM}, 0.15 \mathrm{mM}$, and $0.20 \mathrm{mM}$ were obtained by dilution of a stock standard solution. The plasma standards incorporated $14 \mathrm{mM}$ sodium chloride, $50 \mathrm{mM}$ perchloric acid, and a $1: 5$ dilution of diluting solution $A$. The other series of standards incorporated $\vec{c}$ a 1 : 25 dilution of diluting solution $B$.

PLASMA Ten millilitres of the prepared supernatant, $\vec{c}$ corresponding to a $1: 8$ plasma dilution, were mixed $\subseteq$ with $2.5 \mathrm{ml}$. of diluting solution A. The final EDTASr concentration was therefore $10 \mathrm{mM}$, while the concen- $\vec{\theta}$ tration of potassium carbonate was sufficient to neutralize the perchloric acid precipitant. Originally it was intended to precipitate the potassium perchlorate by cooling, but this extra step was omitted when it was found that depression of magnesium emission by potassium per- $\bar{\partial}$ chlorate was almost eliminated in the presence of the diluting solution.

The total plasma dilution was $1: 10$. Deproteinization introduces error due to the solid content of plasma but it has been calculated above that, under these conditions, this increased the readings by $1 \%$ or less. With the diluting solution and standards described, it appeared from the results in Table $I$ that interfering substances in plasma depressed magnesium emission by $1 \%$ or less. These two small errors, operating in opposite directions, were neglected.

URINE AND FAECES One millilitre of urine, or $5 \mathrm{ml}$. of faecal ash solution, was mixed with $1 \mathrm{ml}$. of diluting 음 solution B, and diluted to $25 \mathrm{ml}$. The final EDTASr and potassium carbonate concentrations were each $10 \mathrm{mM}$.

\section{RESULTS}

In the absence of a generally accepted method of $\stackrel{N}{N}$ measuring magnesium in biological materials we $\omega$ depended upon internal methods of assessing the reliability of the present method, namely, recovery experiments and serial dilutions of identical samples. \&

The results of 12 recovery experiments on plasma are reported in Table II. Magnesium sulphate was added to each plasma sample before deproteinization, raising the concentration by $1.0 \mathrm{mM}$. The mean recovery was $99.1 \%$ and the scatter was small. Even $\varrho$ better results were obtained in the recovery experiments reported in Table III, in which the magnesium 
TABLE II

RECOVERY OF 1.0 MM MAGNESIUM ADDED TO EACH OF 12 PLASMa SAMPLES

$\begin{array}{ccc}\text { Plasma } \mathbf{M g}(\mathbf{m M}) & \begin{array}{c}\text { Plasma }+ \text { Added } \mathbf{M g} \\ (\boldsymbol{m M})\end{array} & \begin{array}{c}\text { Percentage Recovery } \\ 0.62\end{array} \\ 0.63 & 1.61 & 99 \\ 0.66 & 1.60 & 97 \\ 0.82 & 1.64 & 98 \\ 0.83 & 1.80 & 98 \\ 0.83 & 1.82 & 99 \\ 0.84 & 1.84 & 101 \\ 0.86 & 1.81 & 97 \\ 0.91 & 1.84 & 98 \\ 0.91 & 1.93 & 102 \\ 0.95 & 1.94 & 103 \\ 0.95 & 1.93 & 98 \\ & 1.94 & 99 \\ & & \text { Mean } 99.1 \\ & & \text { S.D. } 1.9\end{array}$

levels of 10 urine samples were raised by $2 \mathrm{mM}$, and in Table IV, in which magnesium was added to samples of faeces. In the recovery experiments on faeces, magnesium was added sometimes before ashing and sometimes afterwards, the results being reported separately.
TABLE III

RECOVERY OF 2.0 mM MAGNESIUM ADDED TO EACH OF 10 URINE SAMPLES

\begin{tabular}{ccc} 
Urine Mg $(\mathrm{mM})$ & $\begin{array}{c}\text { Urine } \\
(\mathrm{mM})\end{array}$ & Percentage Recovery \\
\hline 0.84 & 2.83 & $99 \cdot 5$ \\
1.59 & 3.58 & $99 \cdot 5$ \\
1.60 & 3.63 & $101 \cdot 5$ \\
1.78 & 3.80 & 101 \\
1.90 & 3.90 & 100 \\
2.20 & 4.18 & 99 \\
2.28 & 4.26 & 99 \\
2.90 & 4.86 & 98 \\
3.03 & 5.05 & 101 \\
3.35 & 5.33 & 99 \\
& & Mean 99.7 \\
& & S.D. 1.1
\end{tabular}

A further check was made by analysing several different volumes of identical plasma and urine samples. Fig. 3 shows that when $1 \mathrm{ml}$., $2 \mathrm{ml}$., $3 \mathrm{ml}$., and $4 \mathrm{ml}$. portions of the same plasma sample were treated as described above, adjusting the volume of water added after deproteinization to keep the final dilution factor constant, the magnesium results

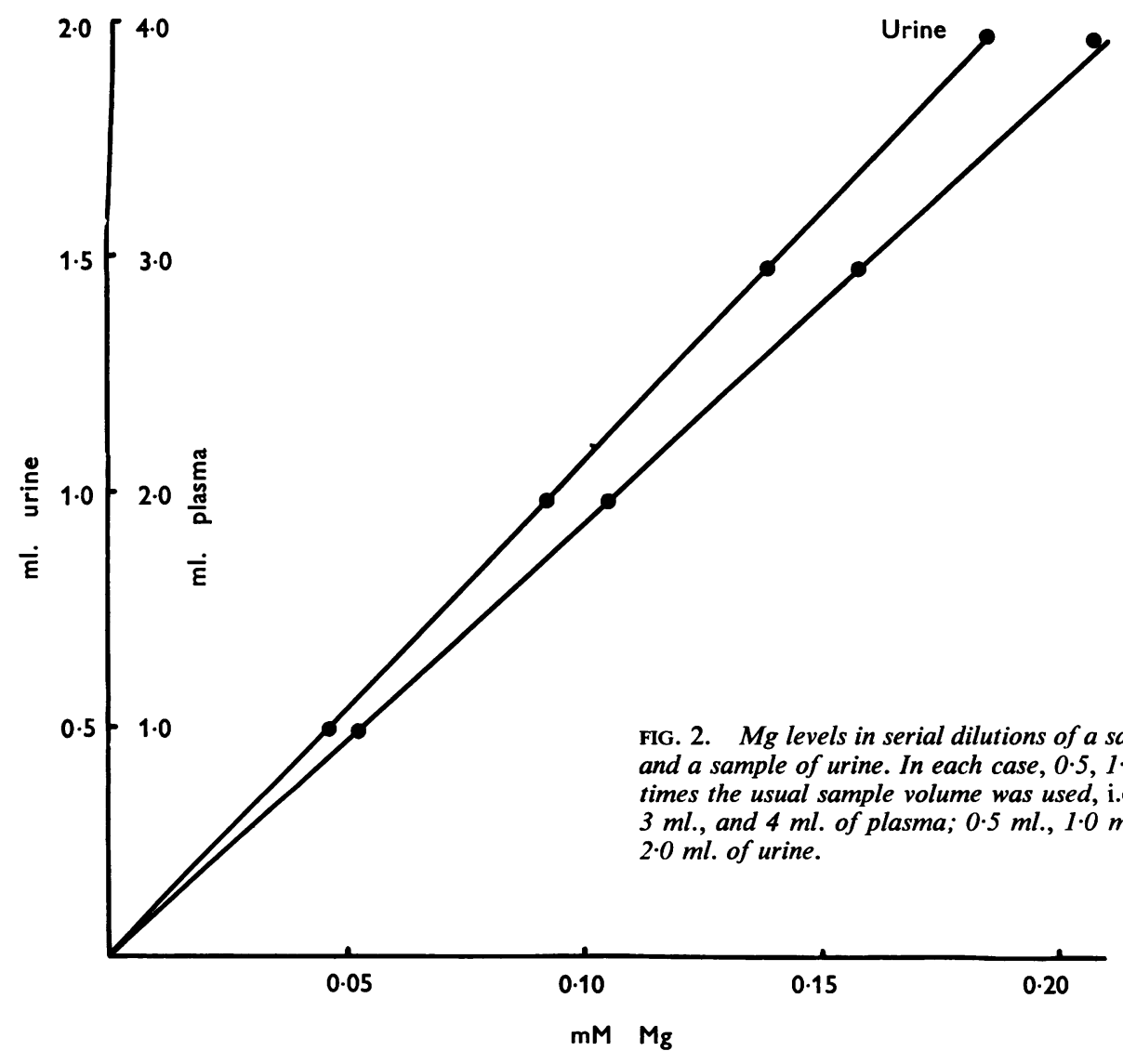


TABLE IV

RECOVERY OF MAGNESIUM ADDED TO SAMPLES OF FAECES TO RAISE Mg LEVEL IN ASH SOLUTION BY $0.5 \mathrm{mM}$
Initial Faecal $\mathbf{M g}^{\mathbf{1}}$
$(\boldsymbol{m M})$

0.22

0.26

$0 \cdot 27$

0.32

0.35

0.37

0.40

0.40

0.41

0.41

0.42

0.42

0.42

0.47

0.52

0.52

0.54

0.58
Percentage Recovery

(a)

\begin{tabular}{r}
$\overline{98}$ \\
100 \\
102 \\
101 \\
100 \\
101 \\
- \\
- \\
102 \\
99 \\
100 \\
- \\
100 \\
98 \\
- \\
99 \\
\hline \\
Mean $100 \cdot 0$ \\
1.3
\end{tabular}

$1 \cdot 3$

${ }^{1}$ In terms of concentration in faecal ash solution (b) $\mathrm{Mg}$ added after ashing.

obtained were in proportion to the volume of plasma used. Fig. 2 also shows that when $0.5 \mathrm{ml}$., $1.0 \mathrm{ml}$., $1.5 \mathrm{ml}$., and $2.0 \mathrm{ml}$. portions of the same urine sample were diluted to $25 \mathrm{ml}$, the magnesium results obtained were proportional to the volume of urine analysed. These internal checks on the methods used confirmed that interference effects were adequately controlled.

The mean plasma magnesium level found in $\mathbf{1 0}$ healthy subjects was $0.87 \mathrm{mM}$ (S.D. $0.035 \mathrm{mM}$ ).

\section{DISCUSSION}

In the measurement of magnesium, flame photometry has distinct advantages over absorptiometric procedures, which are of limited accuracy, or titration with EDTA, which involves either prior separation of magnesium from calcium or calculation from the difference of two titration figures. On the other hand, the newer technique of flame atomic absorption spectroscopy has several advantages over flame emission. It is more sensitive and spectral interference by sodium is avoided. But indirect interference by anions and cations, affecting the absorption by magnesium itself, must be controlled by methods similar to those described for flame emission. As there is no overall advantage in replacing flame emission by flame absorption for the measurement of sodium, potassium, and calcium, economic reasons may dictate the choice of flame emission for magnesium also.

The special problems in measuring magnesium by flame photometry are its much lower emission energy, even than calcium, the spectral interference by sodium, the effects of solutes on flame background, and indirect interference effects altering the emission by magnesium itself.

Van Fossan, Baird, and Tekell (1959) increased magnesium emission by incorporating high concentrations of organic solvents, but in our experience this decreased flame stability, presented explosion $\stackrel{\infty}{\omega}$ risks because of the separate spray chamber, and $\vec{O}$ necessitated special precautions to prevent the evaporation of solutions.

The molecular bands of magnesium have greater emission intensity than the atomic resonance line? at $285.2 \mathrm{~m} \mu$ and were used in most of the early work $\vec{P}$ on the determination of magnesium in biological materials. Instrumental improvements in sensitivity permit measurement at the much more selective atomic line, as has been shown by Alcock et al. (1960).

The instrument and conditions employed by us differed from those of Alcock and her colleagues in several respects. The instrument was designed to use $\mathscr{G}$ compressed air instead of oxygen. While this was more convenient, there was some loss of sensitivity. This in turn, together with the difficulty of ensuring exactly reproducible wavelength settings with the extremely narrow slit width of $0.02 \mathrm{~mm}$. selected by Alcock et al. (1960), determined our choice of a $\varrho$ $0.08 \mathrm{~mm}$. slit width. Our magnesium: flame back- $\overrightarrow{\overrightarrow{0}}$ ground emission ratio was consequently lower, and fluctuation of flame background could contribute $\supsetneq$ substantially to instrumental instability. We found, however, that total stability was satisfactory, and as good using $0.2 \mathrm{mM}$ as using $0.5 \mathrm{mM}$ magnesium, with its correspondingly higher magnesium: flame $\frac{3}{3}$ background emission ratio. This ratio, considered in isolation, is thus not an indication of instrumental performance.

Spectral interference by sodium was greater with a $0.08 \mathrm{~mm}$. slit width than with one of $0.02 \mathrm{~mm}$., but $\frac{7}{2}$ it was easy to control when the sodium concentration was known. Using the dilution procedure described, $\mathcal{N}$ even if the plasma sodium level was not known, $N$ variation within the range 120 to $160 \mathrm{mM}$ contri- N buted errors of less than $2 \%$. If correction for urine $\omega$ sodium was not made, errors in magnesium results were usually about $2 \%$, and were less if an average $\stackrel{\circ}{\frac{0}{C}}$ figure of, say, $50 \mathrm{mM}$ sodium was assumed.

Using the dilution methods described, potassium? was the only biological solute found to affect flame background and this effect was not measurable with $\bar{D}$ the concentration of potassium in plasma or faeces. $\frac{\varrho}{\Phi}$ In urine, correction on the basis of the known potas- $\varrho$ sium content rarely exceeded $1 \%$ of the magnesium level. 
Indirect interference effects were almost entirely eliminated by dilution in a solution containing the strontium salt of EDTA and potassium carbonate. This was preferred to attempting to create the same degree of interference in the standards as in the unknowns by synthesizing complex standard solutions with a composition approximating to that of the solutions analysed (Alcock et al., 1960).

The strontium salt of EDTA was more efficient in maintaining magnesium emission than other EDTA salts, and unlike the disodium salt, caused no spectral or background interference. Its efficiency was also greater than that of strontium chloride, which was among the inorganic releasing agents we had tested previously, and this demonstrated that its action was not due merely to the releasing agency of strontium.

The method described here has been found satisfactory in the analysis of other materials, such as diets, bone, and soft tissues. As none of these presents greater interference problems than plasma and urine, results of recovery experiments have not been included.

The plasma magnesium levels found in healthy subjects, although too few to establish a normal range, are similar to the levels reported by Van Fossan et al. (1959) and Alcock et al (1960).

We would like to express our gratitude to Professor N. F. Maclagan and to the British Empire Cancer Campaign for making available to us the flame spectrophotometer used in this work.

\section{REFERENCES}

Alcock, N., MacIntyre, I., and Radde, I. (1960). J. clin. Path., 13, 506.

Fawcett, J. K., and Wynn, V. (1961). Ibid, 14. To be published.

Van Fossan, D. D., Baird, E. E., and Tekell, G. S. (1959). Amer. J. clin. Path., 31, 368.

West, A. C., and Cooke, W. D. (1960). Analyt. Chem., 32, 1471. 